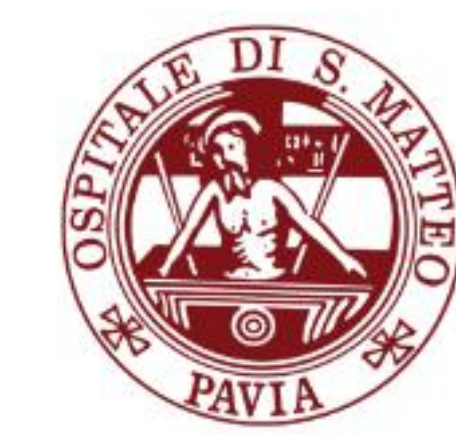

Fondazione IRCCS
Policlinico San Matteo

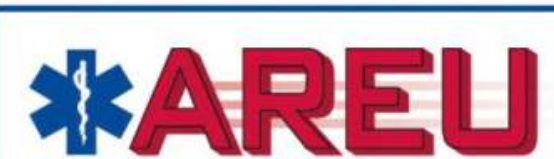 AZIENDARELIONALE R Regione}

\section{Post ROSC Perfusion Index and survival after out-of- hospital cardiac arrest. An update of our results.}

Simone Savastano, MD; Enrico Baldi, MD; Elisa Cacciatore, MD; Giulia Bellini, MD; Fabrizio Canevari, RN; Alessandra Palo,MD; Giorgio A. lotti, MD; Gaetano M. De Ferrari, MD; Luigi Oltrona Visconti, MD.

Sistema Socio Sanitario

\section{Regione} Lombardia

ASST Pavia

Purpose. Prognostication after out of hospital cardiac arrest (OHCA) is still now an open issue. About this topic we have explored, for the first time, the potential role of the post ROSC peripheral perfusion index as a predictor of 30 days survival. Our aim was to confirm our preliminary results on a larger population. Methods. We retrospectively evaluated the reports generated by the manual monitor/defibrillator (Corpuls by GS Elektromedizinische Geräte G. Stemple $\mathrm{GmbH}$, Germany) used for cases of OHCA in which ROSC was achieved, from January 2015 to December 2017. The mean values of PI were automatically provided in the report every minute after ROSC and the mean value of 30 minutes of monitoring $\left(\mathrm{MPI}_{30}\right)$ was calculated. The duration of cardiac arrest, the type of presenting rhythm (shockable or not shockable) and the total amount of epinephrine administered were also computed.

2246 patients enrolled in the Pavia CARe from January 2015 to December 2016

\section{In 1403 CPR has been attempted}

299 with pre-hospital ROSC

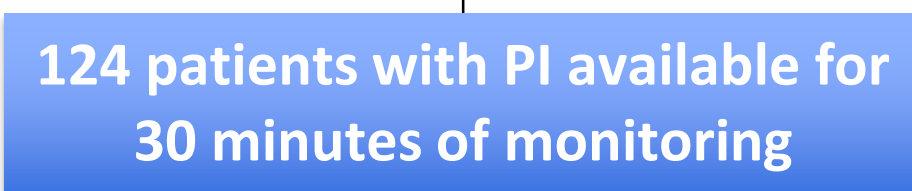

53 alive@ 30

71 dead @ 30 days days

RESUSCITATION 2018 New technologies in resuscitation $20-21-22$ September $\bullet$ Bologna $\bullet$ Italy
Results. On 2246 OHCA enrolled in our provincial cardiac arrest registry (Pavia CARe) a resuscitation was attempted in 1403 cases and a ROSC was achieved in 241. The mean value of PI during 30 minutes of monitoring $\left(\mathrm{MPI}_{30}\right)$ after ROSC was available in 124 patients. Survived patients showed significantly higher values of $\mathrm{MPI}_{30}[1.4(95 \% \mathrm{Cl} 0.9-2.7)$ vs $1(95 \% \mathrm{Cl} 0.8-1.3) \mathrm{p}=0.02]$. At multivariable Cox regression model $\mathrm{MPI}_{30}$ was an independent predictor of death at 30 days [HR $\left.0,8(95 \% \mathrm{Cl} 0.6-0.98) \mathrm{p}=0.036\right]$. Moreover, patients with value of MPI30 $\geq 2,5$ showed a better 30 days survival [HR 2,1 (95\%Cl 1.2-3.6) $\mathrm{p}=0.017]$. An inverse correlation was found between the total amount of epinephrine administered corrected for the duration of cardiac arrest and the $\mathrm{MPI}_{30}(\mathrm{Spearman}$ 's Rho $-0.3 p<0.01)$

\begin{tabular}{|r|c|c|c|}
\hline \multicolumn{5}{|c|}{ Cox univariable model for death @ 30 days } \\
\hline Variable & HR & $95 \% \mathrm{Cl}$ & $\mathrm{P}$ \\
\hline MPI30 & 0,85 & $0,7-0,99$ & 0,09 \\
\hline PI@1 min & 0,94 & $0,8-1,1$ & 0,31 \\
\hline PI@10 min & 0,9 & $0,8-1$ & 0,19 \\
\hline OHCA duration $(\mathrm{min})$ & 1,01 & $1,01-1,03$ & $<0,001$ \\
\hline Non shockable rhythm & 4,14 & $2,4-7,1$ & $<0,001$ \\
\hline SBP $(\mathrm{mmHg})$ & 0,99 & $0,98-1$ & 0,15 \\
\hline DBP $(\mathrm{mmHg})$ & 0,99 & $0,98-1$ & 0,38 \\
\hline MPI30: 30 minutes monitoring mean value of Pl \\
\hline
\end{tabular}

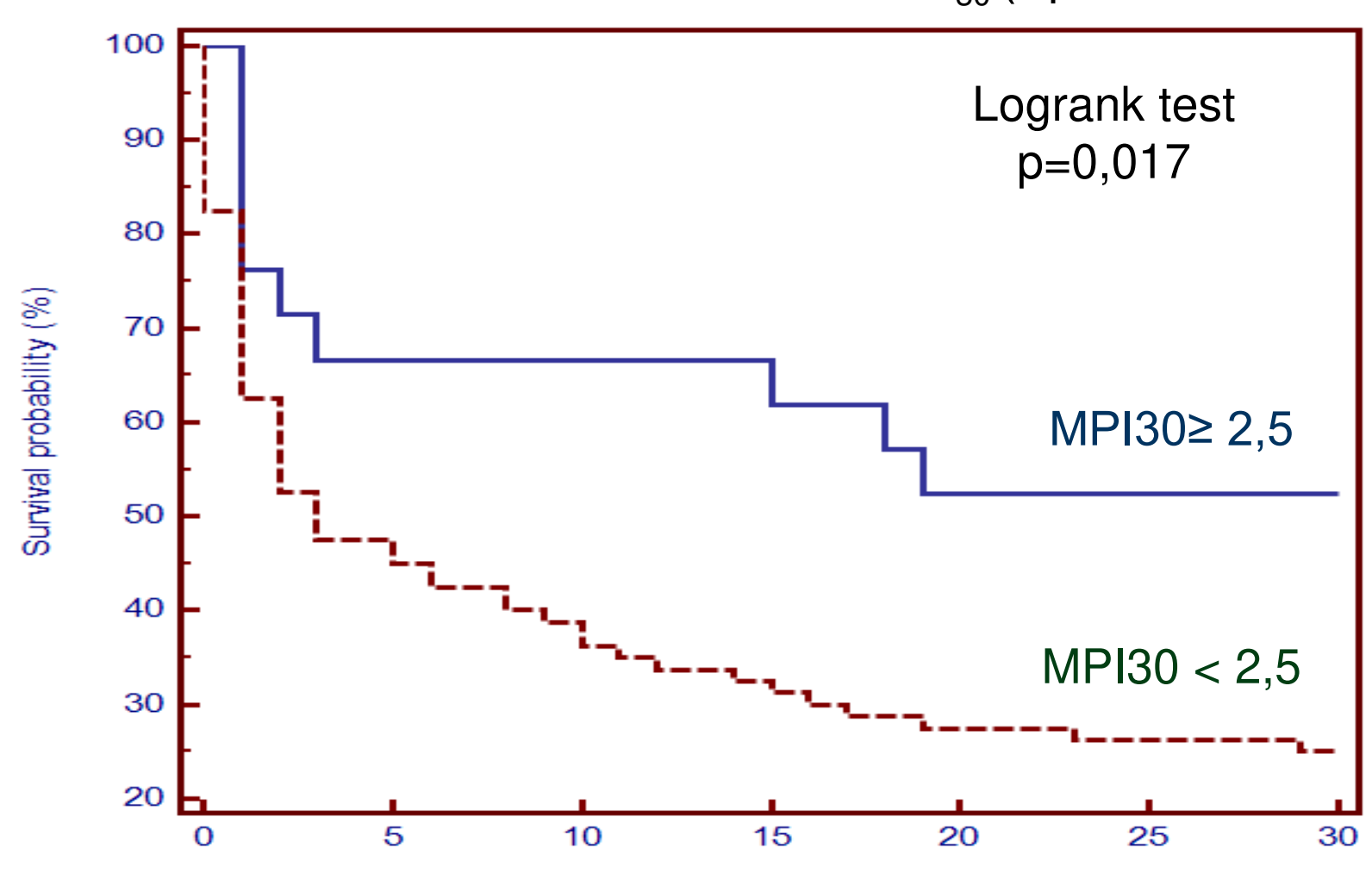

SBP: systolic blood pressure; DBP: diastolic blood pressure

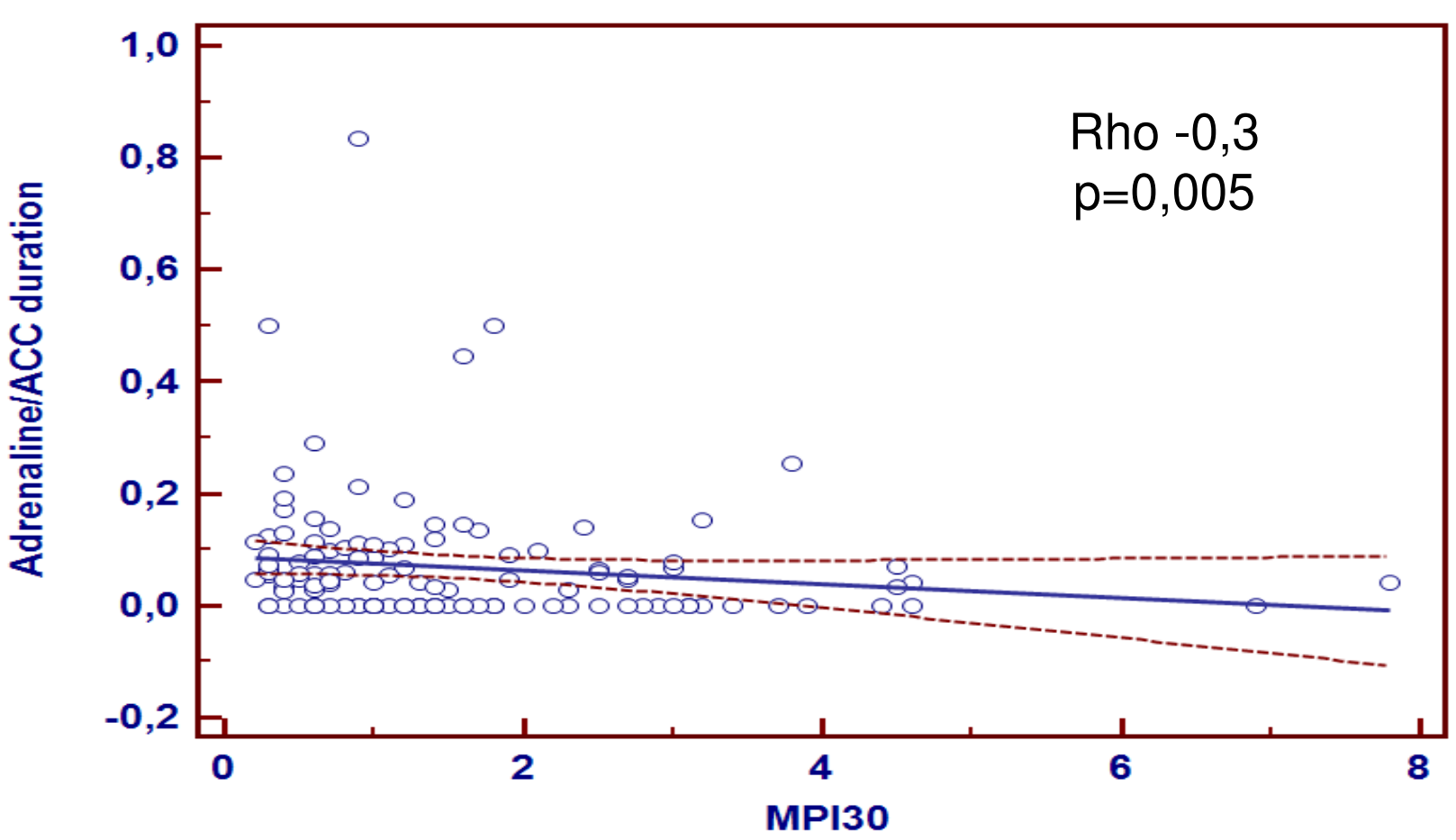

Conclusions. Our results confirmed on a larger
Low perfusion

emitted light $\sim$

received light

Absorption

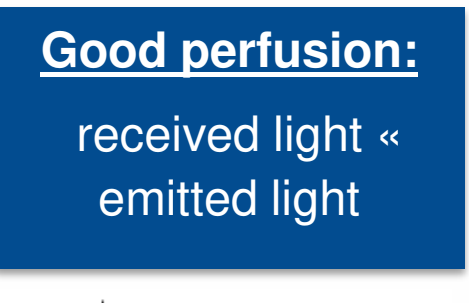

absoppion MIIMIMIMI population the potential role of peripheral perfusion index as a predictor of 30 days survival after an outof-hospital cardiac arrest. 